\title{
Eliminating the Shrinkage of High Strength Concrete by using Super Absorbent Polymer (SAP)
}

\author{
Suhad M Abd, Baidaa Khdheer Ahmed \\ Department of Civil Engineering, College of Engineering, University of Diyala
}

BaidaaKhdheer@gmail.com

\begin{abstract}
High Strength Concrete (HSC) is one of the most popular types of concrete used in the world. This type of concrete has a low rapid hydration of cementation materials with low $\mathrm{w} / \mathrm{cm}$ and the external surrounding environment condition exposed the HSC to high autogenous shrinkage. If this shrinkage is not treated well that well led to cracking, in this case HSC need to convenient curing necessary at the earliest time. This study presents the use of Super Absorbent Polymer (SAP) as internal curing agent to eliminate shrinkage. Two types of shrinkage are tested in this study (Autogenous shrinkage and drying shrinkage).

Two groups of concrete mixes(A and B) are studied in this study each group have five types of concrete mixes, four mixes with high and ultra-high compressive strength (RPC, MRPC, HSC and SCC) and the last one with normal compressive strength (NSC). Group A represent concrete mixes without SAP addition and group B for concrete mixes with SAP. SAP was added for all mixes at $0.3 \%$ by weight of cement and adding $20 \mathrm{ml}$ water for each gram of SAP, specimens with dimensions $(40 * 40 * 160) \mathrm{mm}$ were used for testing shrinkage for each mix with and without SAP, average values for two specimens was taken as a results. It was found that concrete mixes of group B have lower shrinkage than the shrinkage of concrete mixes in group A at 28 days age with reduction of autogenous shrinkage(AS) of $(57 \%, 35 \%, 37 \%, 44.5 \%$ and $37.5 \%$ ) respectively and for drying shrinkage the percentage of reduction was $(89.5 \%, 72 \%$, $82 \%, 70 \%$ and $71 \%$ ) respectively, addition of SAP to concrete mixes proves to have active effect in reducing the shrinkage of concrete.
\end{abstract}

Keywords: Superabsorbent Polymer (SAP), High-Strength Concrete(HSC), Internal curing IC,Drying Shrinkage DS, Autogenous Shrinkage AS.

Paper History: (Received: 2/1/2017; Accepted: 9/4/2017)

\section{Introduction}

HSC with a low water- cement ratio has become widely used in the last decades; it is very sensitive to the risk of shrinkage unless special curing is taken, external curing is not enough to reduce this risk. Internal curing (IC) is very promising technique that can provide additional water in concrete for more effective hydration of the cement and reduced selfdesiccation [1]. There are two main methods available for IC of concrete, light weight aggregate used as the first method to supply water for concrete, which can replace the water losses by chemical shrinkage during cement hydration [3], the other method is the use of super absorbent polymer (SAP) , particle of SAP can absorb large quantity of water during mixing of concrete if added in dry state as powder, particles of SAP that contains water prevent self-desiccation during cement hydration [3], and complete the hydration process ,IC is not a substitute for external curing [4]. In this research used IC to elimination shrinkage of concrete that lead to crack then failure in structure.

\section{Internal Water Curing of Concrete}

High strength concrete (HSC) contain insufficient mixing water due to design requirement to obtain high compressive strength with low w/c ratio. In order to maintain the water filled coarse capillaries needed to sustain cement hydration and pozzolanic_reaction, it is needed to add water .Internal water is more effective for this type of concrete; this water can conquer the problems of low w/c ratio and low permeability, which can't be solved by external curing method. As a result, the use of internal curing can reduce shrinkage [5]. For supply internal water there are two methods, the first one by use presaturated light weight aggregate LWA and the second by use super absorbent polymer SAP, in this study second method was used, And the most studies have showed that internal curing by the use of SAP has less chloride penetration than IC by using LWA [1]. SAP can be used as internal water reservoir to eliminate shrinkage 
in concrete. This is due to the ability of SAP particles to absorb amount of water times its weight and release it when the condition of surrounding environment change. During concrete mixing, particles of SAP began to absorb water; this water is consumed during cement hydration, provided IC to the surrounding concrete matrix and preventing self-desiccation [6]. IC using SAP and an extra amount of water reduce the shrinkage of concrete with low water to blinder ratio, this effect becomes more clear with increasing amount of SAP and extra water [10].

\section{Expermintal Investigation \\ 3.1 Materials}

Four mixes (Reactive Powder Concrete RPC, Modified Reactive Powder Concrete MRPC, High Strength Concrete HSC and Self Compact Concrete SCC) with high and ultrahigh compressive strength and one mix (Normal Strength Concrete NSC) with normal strength concrete were produced in this study. Different materials are used in these mixes. Cement used in this research was commercially available ordinary portland cement with the trade mark of (Tasloja), the physical and chemical properties of this cement type are existing in Tables 1 and 2 respectively.. Coarse aggregate with a maximum particle size of (12.5) $\mathrm{mm}$ for (MRPC, HSC and SCC) and maximum particle size of (19.5) $\mathrm{mm}$ for NSC are used.The sieve analysis of this two type of coarse aggregate as shown in Tables 3 and 4 respectively. AlAkhaider sand with specific gravity of 2.6 $\mathrm{kg} / \mathrm{m}^{3}$ was used in three concrete mixes (SCC,NSC and HSC), the sieve analysis is shown in Table 5. Imported fine standard sand, it has grade particle $\leq 600 \mu \mathrm{m}$ was used in (RPC and MRPC), the sieve analysis of this type is shown in Table 6. Silica fume was used with two replacement ratios $(25 \%-8.38 \%)$ by weight of cement, Micro silica considered most reactive than any other natural pozzolana the properties of this type of silica is shown in Table7. Glienum 51 was used as superplasticizer with different dosage this type of superplastisezer is free from chlorides the properties of this type is shown in Table 8 . Steel fiber with $(50 \mathrm{~mm})$ length used with two mixes (RPC and MRPC) and its properties shown in Table 9, at the end SAP added to concrete with percentage $0.3 \%$ weight of cement, the dosage of external water was 20 $\mathrm{ml}$ for each gram of SAP addition and its properties shown in Table 10.

Superabsorbent polymer(SAP) is a material that have ability to absorb and release large amount of water and pore solutions, two type of SAP found, acrylic acid monomer will deprotonate at $\mathrm{pH}>5$ and the acrylamide monomer at $\mathrm{pH}$ is $\sim 12$ or above [8], in this study it has been grinding SAP particle to a smaller size to ensure good distribution and smaller voids for these particles this is because when added SAP with big particle in initial experiments noticed that the particles when absorb water and volume increased lead to crash in many parts of concrete specimens especially in the rims of specimens and left large voids inside concrete after it loss water . It supply by Areej Al-Furat Company.

Table 1 Physical properties of the cement.

\begin{tabular}{|c|c|c|}
\hline Physical Properties & Test Results & $\begin{array}{c}\text { Iraqi Specification } \\
\text { No. 5/1984 }\end{array}$ \\
\hline $\begin{array}{c}\text { Fineness using Blaine air } \\
\text { permeability apparatus(m²/kg) }\end{array}$ & 405 & $230^{* *}$ \\
\hline $\begin{array}{c}\text { Setting time using Vicat's } \\
\text { instruments } \\
\text { Initial(min.) } \\
\text { Final(hr) }\end{array}$ & 135 & \\
\hline $\begin{array}{c}\text { Compressive strength for } \\
\text { cement Paste Cube(70.7mm) }\end{array}$ & $3: 25$ & $45^{* *}$ \\
at: & 24.4 & $10^{*}$ \\
3days(MPa) & 32.3 & $15^{* *}$ \\
7days(MPa) & & $23^{* *}$ \\
* Maximum & & \\
**Minimum & & \\
\end{tabular}

Table 2 Chemical composition of the cement.

\begin{tabular}{|c|c|c|}
\hline $\begin{array}{c}\text { Chemical } \\
\text { Composition }\end{array}$ & \%(weight) & $\begin{array}{c}\text { Iraqi } \\
\text { Specification } \\
\text { No. 5/1984 }\end{array}$ \\
\hline Lime $\mathrm{CaO}_{2}$ & 61.19 & - \\
\hline $\mathrm{Sili}_{2}$ & 21.44 & - \\
\hline $\mathrm{Alumina}_{2} \mathrm{Al}_{2} \mathrm{O}_{3}$ & 4.51 & - \\
\hline Iron Oxide $\mathrm{Fe}_{2} \mathrm{O}_{3}$ & 3.68 & - \\
\hline Magnesia $\mathrm{MgO}$ & 2.31 & 5 \\
\hline Sulfate $\mathrm{SO}_{3}$ & 2.7 & $2.8^{*}$ \\
\hline Loss on ignition L.O.I & 2.39 & $4.0^{*}$ \\
\hline Insoluble residue I.R & 1.18 & $1.5^{*}$ \\
\hline Lime saturation factor L.S.F & 0.87 & $0.66-1.02$ \\
\hline Tricalcium aluminates $\mathrm{C}_{3} \mathrm{~A}$ & 5.73 & - \\
\hline Tricalcium silicate $\mathrm{C}_{3} \mathrm{~S}$ & 42.83 & - \\
\hline Dicalcium silicate $\mathrm{C}_{2} \mathrm{~S}$ & 29.4 & - \\
\hline Teracalcium alumina ferrite $\mathrm{C}_{4} \mathrm{AF}$ & 11.19 & - \\
\hline
\end{tabular}

Table 3 Grading of coarse aggregate size (5-19mm).

\begin{tabular}{|c|c|c|}
\hline Sieve Size (mm) & Passing \% & $\begin{array}{c}\text { Iraqi Specification No. } \\
\mathbf{4 5 / 1 9 8 4} \text { for Zone(2) }\end{array}$ \\
\hline 20 & 95.6 & $95-100$ \\
\hline 10 & 31 & $30-60$ \\
\hline 5 & 1 & $0-10$ \\
\hline Pan & Zero & Zero \\
\hline
\end{tabular}

Table 4 Grading of coarse aggregate size $\leq 12.5 \mathrm{~mm}$.

\begin{tabular}{|c|c|c|}
\hline Sieve Size (mm) & Passing \% & $\begin{array}{c}\text { Iraqi Specification No. } \\
\text { 45/1984 for Zone(2) }\end{array}$ \\
\hline 12.5 & 100 & $90-100$ \\
\hline 10 & 88.7 & $50-85$ \\
\hline 4.75 & 0.51 & $0-10$ \\
\hline Pan & Zero & zero \\
\hline
\end{tabular}


Table 5 Grading of fine aggregate.

\begin{tabular}{|c|c|c|}
\hline Sieve Size & Passing \% & $\begin{array}{c}\text { Iraqi Specification No. } \\
\mathbf{4 5 / 9 8 4} \text { for Zone(2) }\end{array}$ \\
\hline $4.75 \mathrm{~mm}$ & 93 & $90-100$ \\
\hline $2.7 \mathrm{~mm}$ & 83.4 & $75-100$ \\
\hline $1.18 \mathrm{~mm}$ & 69 & $55-90$ \\
\hline $600 \mu \mathrm{m}$ & 47.31 & $35-59$ \\
\hline $300 \mu \mathrm{m}$ & 15.405 & $8-30$ \\
\hline $150 \mu \mathrm{m}$ & 0.707 & $0-10$ \\
\hline Pan & zero & Zero \\
\hline
\end{tabular}

Table 6 Grading of silica sand.

\begin{tabular}{|c|c|}
\hline Siere Size & Passing \% \\
\hline $600 \mathrm{~mm}$ & 93 \\
\hline $300 \mathrm{~mm}$ & 23 \\
\hline $150 \mathrm{~mm}$ & 4.5 \\
\hline Pall & 0 \\
\hline
\end{tabular}

Table 7 Silica Fume Properties.

\begin{tabular}{|c|c|}
\hline Type & Densified Silica fume \\
\hline Form & powder \\
\hline Color & Gray \\
\hline Surface area & $24000-28000 \mathrm{~m} 2 \mathrm{~kg}$ \\
\hline SiO2 & $\geq 90 \%$ \\
\hline SO3 & $\leq 0.2 \%$ \\
\hline $\mathrm{CaO}$ & $\leq 0.8 \%$ \\
\hline
\end{tabular}

Table 8 Gleinum 51 Properties.

\begin{tabular}{|c|c|}
\hline Form & Viscous liquid \\
\hline Color & Light brown \\
\hline Relative density & $1.1 @ 20$ \\
\hline PH & 6.6 \\
\hline Viscosity & $128+1-30$ CPS@ 20 \\
\hline Transport & Not classified as dangerous \\
\hline Labeling & No hazard label required \\
\hline
\end{tabular}

Table 9 Steel Fiber Properties.

\begin{tabular}{|c|c|}
\hline Fiber Length & 2"(50mm) \\
\hline Specific Gravity & $7800 \mathrm{~kg} / \mathrm{m} 3$ \\
\hline Equivalent Diameter & 0.032 "(0.8)mm \\
\hline Tensile strength & $152000 \mathrm{psi}(1050 \mathrm{MPa})$ \\
\hline Appearance & Bright and clean wire \\
\hline Deformation & Hook End \\
\hline
\end{tabular}

Table 10 Properties of Super Absorbent Polymer SAP.

\begin{tabular}{|c|c|}
\hline Sample name & Agricultural Grade SAP \\
\hline Appearance & White Granules \\
\hline Water retention rate (purwater,ml/g) & $\geq 350$ \\
\hline Gel intensity & Strong \\
\hline Particle size (mesh) & $\begin{array}{c}5-20 \text { mesh,20-80 mesh,30-100 } \\
\text { mesh }\end{array}$ \\
\hline
\end{tabular}

\subsection{Mixture Proportions}

All mixture proportion are present in Table 8 . Addition of SAP equal to $0.3 \%$ by weight of cement, that means the amount of SAP that added to concrete is different in each mixture, the a mount of internal curing IC water was $(20 \mathrm{ml})$ for each gram SAP ,so, the addition of external water(additional water added for SAP) was different for each mix.

Table 8 Properties of concrete mixes.

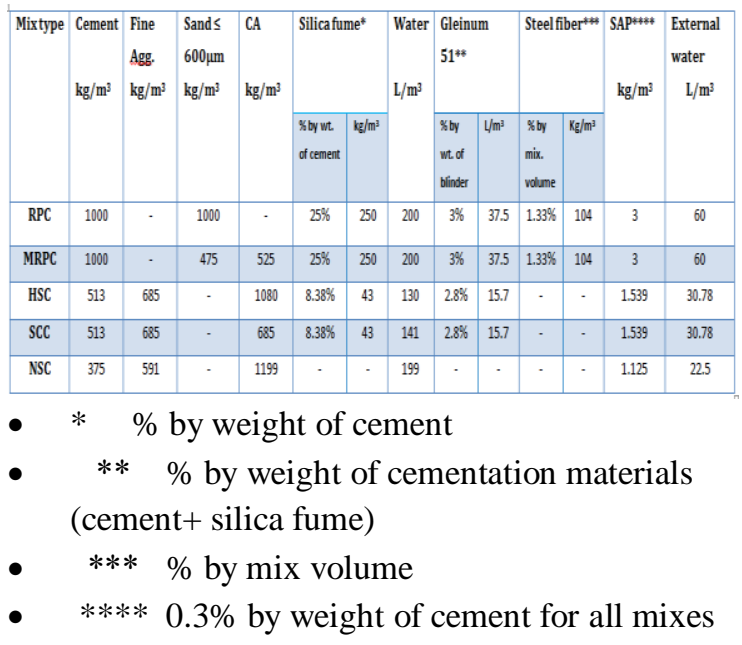

\subsection{Shrinkage Test}

Prismatic with dimension $(40 * 40 * 160) \mathrm{mm}$ specimens were used to measure the length change of concrete sample as shown in Figure 1.

This test has been according to ASTM C15706 [7], the shrinkage was measured by using (length comparator) apparatus. Calculate the length change of any specimen at any age after the initial comparator reading as follows-:

$\Delta L x=[(C R D-$ initial $C R D) / G] * 100$

where-:

$\Delta \mathrm{Lx}$ : length change of sampling at any age $\%$

CRD: difference between the comparator reading of the

Specimen and the reference bar at any age, and $\mathrm{G}$ : the length of specimen.

Average of two prisms was adopted in calculation; the samples used for drying 
shrinkage test were conducted to air (in room temperature). For autogenous shrinkage AS, prismatic with dimension $(40 * 40 * 160) \mathrm{mm}$ that used in this test is envelope by aluminum foil tape to prevent moisture evaporation
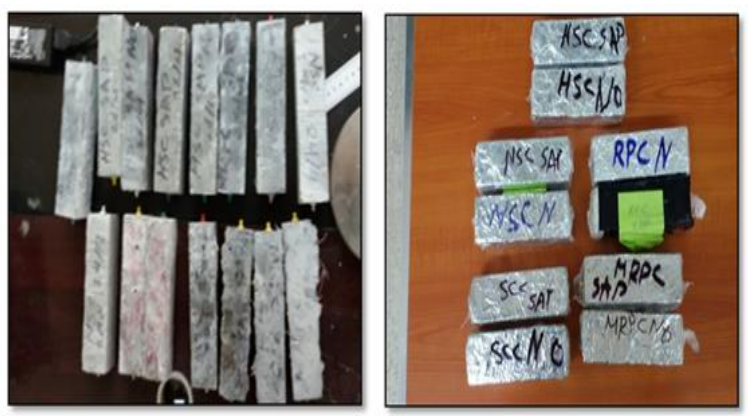

Figure 1: Specimens of Shrinkage

\section{Results and Discussion}

- Drying Shrinkage:-The drying shrinkage is defined as the average change in length of the specimen per unit length due to loss of free water under normal condition. Figures 2 to 6 show the results of all mixes of concrete with and without SAP. In general the test results showed high drying shrinkage at early age due to rapid loss of moisture from the surface of the mixture.After testing mixes at age 28 days for group $\mathrm{B}$ (with SAP) noticed that drying shrinkage is reduced of about $(89.5 \%, 72 \%$, and $82 \%, 70 \%$ and $71 \%)$ for (RPC, MRPC, SCC, HSC and NSC) relative to the corresponding to specimens in group A (without SAP)

- Figures 7 to 11 shows the results of AS test by use length comparator. Autogenous shrinkage of mixes in group B are lower than mix in group $\mathrm{A}$ as follow $(57 \%, 35 \%, 37 \%, 44.5 \%$ and $37.5 \%)$ for (RPC,MRPC,SCC,HSC and NSC)mixes respectively relative to the corresponding to specimens in group $\mathrm{A}$ (without SAP)

In general, the values of AS is lower than of drying shrinkage, this is because AS is the bulk deformation of a closed (sealed), isothermal, cementation material system not subject to external forces.All results which belong to shrinkage gives good indication that IC is very necessary to addressed the shrinkage in concrete.

Water in HSC insufficient to achieve complete hydration of cement, two mechanisms are responsible for the development of shrinkage deformation from self- desiccation, a) decrease in the disjoining pressure between the particles of the C-S-H gel. b) decrease in the menisci radii of the pore water, which increases the tension both within the pore water and at its surface [7]. The decreased of AS and drying shrinkage of internally cured concrete was attributed to the availability of water from the SAP to fill capillary voids formed by shrinkage. Internal curing will improve the degree of hydration and also minimize the development of autogenous shrinkage that's can lead to early- age cracking [9].

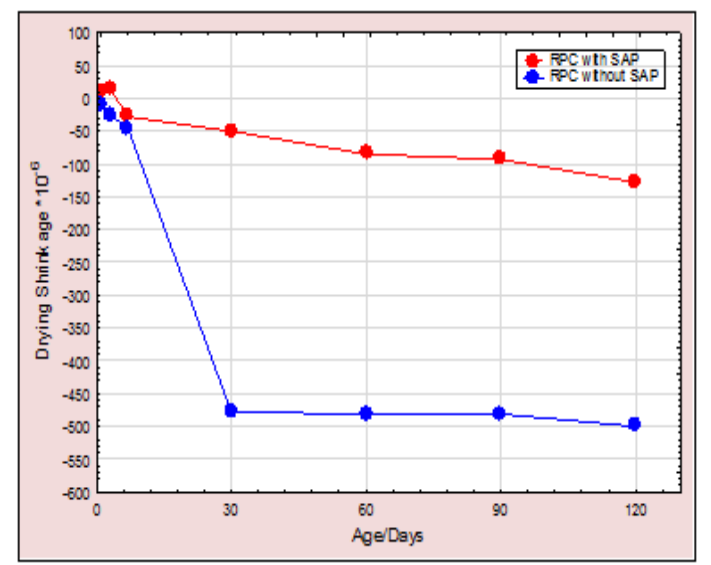

Figure 2: Drying Shrinkage of RPC mixes with and without SAP

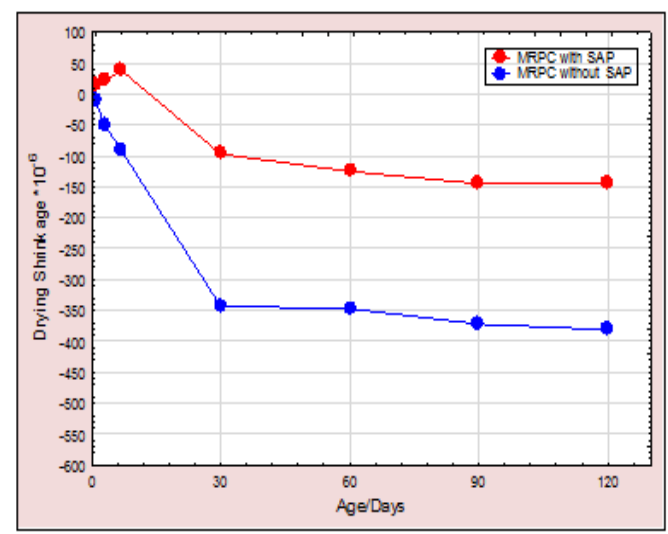

Figure 3: Drying Shrinkage of MRPCmixes with and without SAP

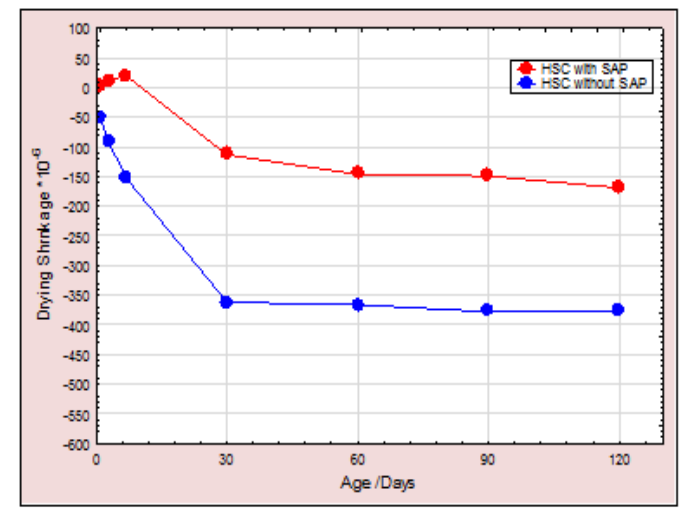

Figure 4: Drying Shrinkage of HSC mixes with and without SAP 


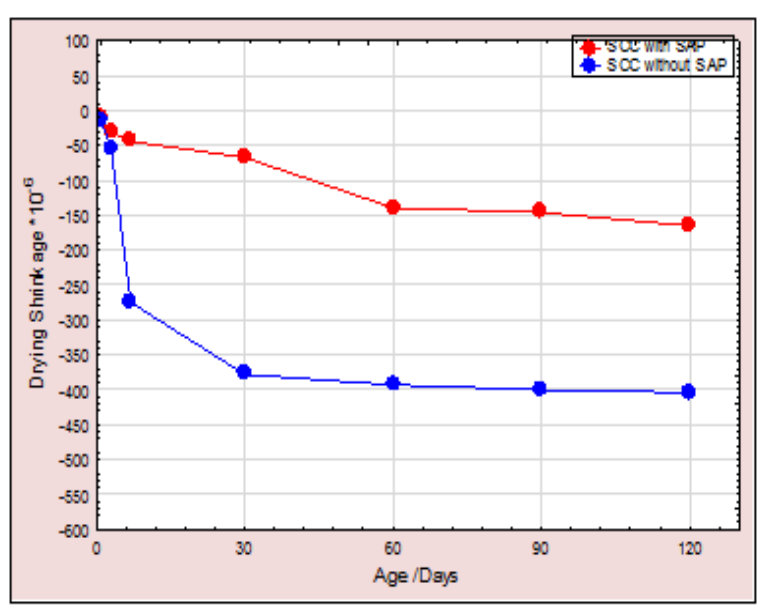

Figure 5: Drying Shrinkage of SCC mixes with and without SAP

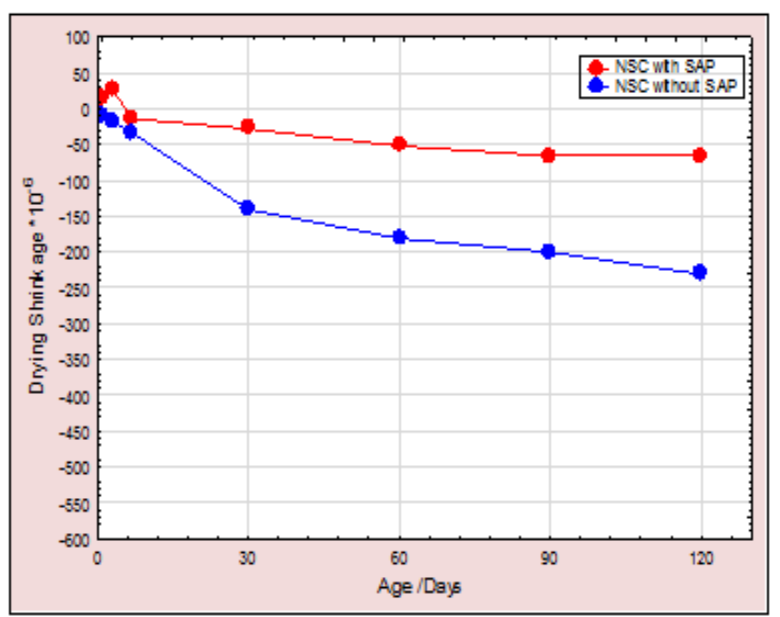

Figure 6: Drying Shrinkage of NSC mixes with and without SAP

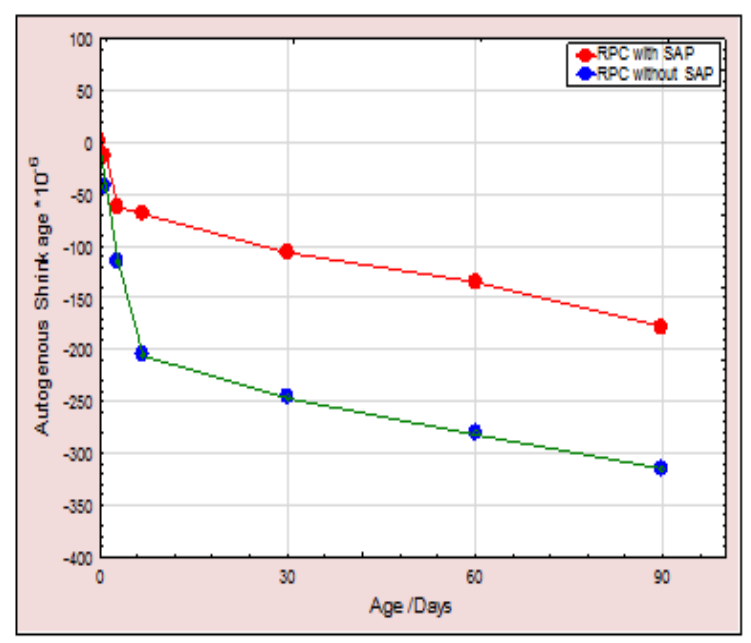

Figure 7: Autogenous Shrinkage of RPC mixes with and without SAP

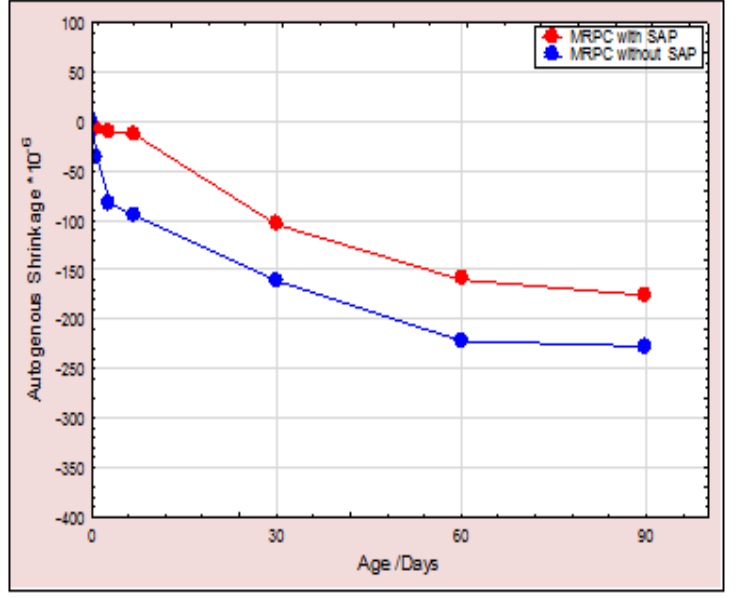

Figure 8: Autogenous shrinkage of MRPC mixes with and without SAP

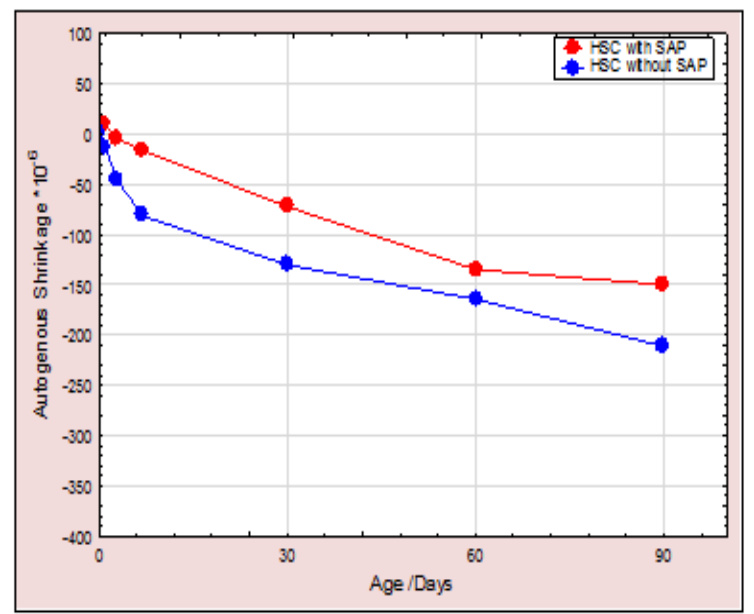

Figure 9: Autogenous Shrinkage of HSC mixes with and without SAP

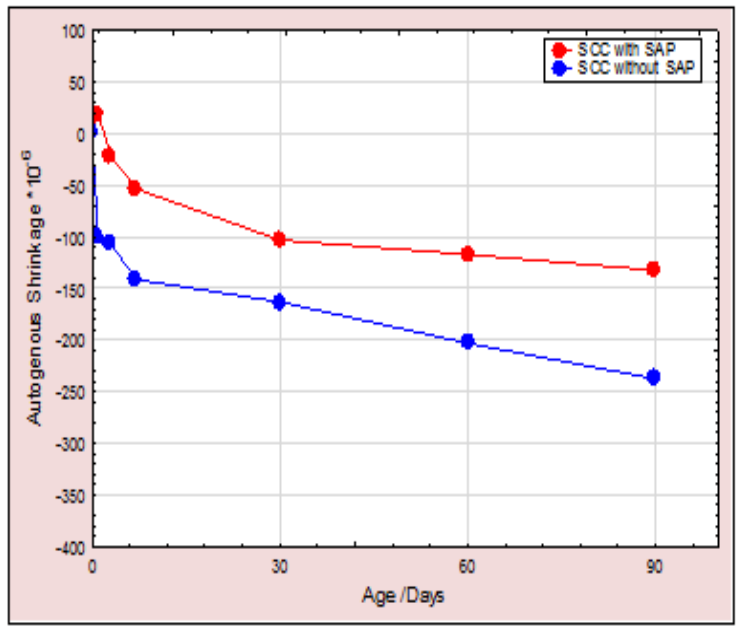

Figure 10: Autogenous Shrinkage of SCC mixes with and without SAP 


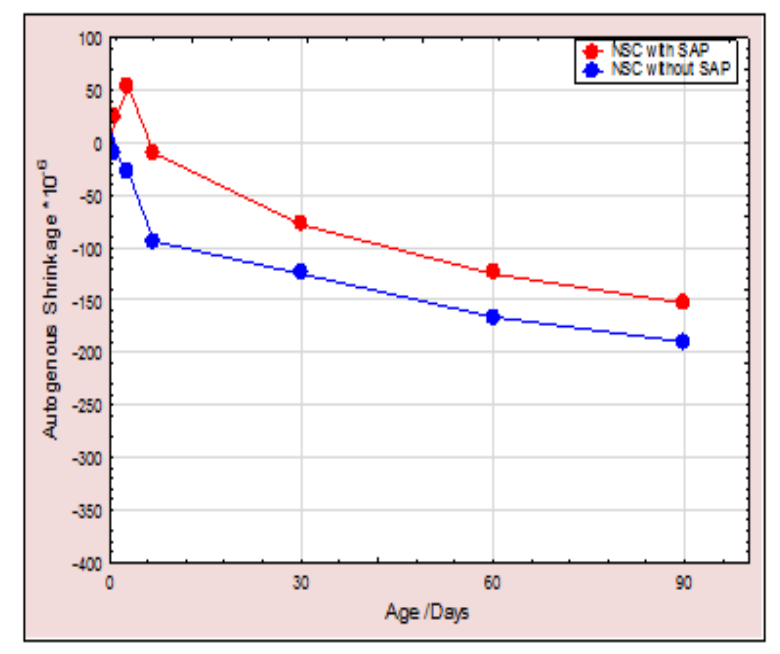

Figure 11: Autogenous Shrinkage of NSC mixes with and without SAP

\section{Concolutions}

This study evaluated the effect of internal curing IC on shrinkage (autogenous and drying)by use SAP addition and external water to concrete mixes and compare the results of shrinkage tests between mixes with and without SAP addition. The main results of this study are summarized as follows:-

- It is clear from all results of testing in this study that AS of all mixes is lower than drying shrinkage.

- The ultimate drying shrinkage of concrete at (28) days decreased with IC water provided by SAP. The results of testing group B , shown the reduction of drying shrinkage by $89.5 \%, 72 \%, 69 \%, 82 \%$ and $80 \%$ )for (RPC, MRPC, HSC, SCC and NSC) respectively, than the results that obtains from group A tests (for samples without SAP)

The ultimate AS of concrete at (28) days decreased with IC water provided by SAP, as a results of testing group $\mathrm{B}$, it shown the reduction of AS $(57 \%, 35 \%, 44.5 \%, 37 \%$ and $37.5 \%$ ) for (RPC,MRPC,HSC,SCC and NSC) respectively, than the results that obtains from group A tests.

\section{Referances}

[1].Gifa,C.C.,Prabavathy,S.,\&Kumar,G.Y., Study on Internal Curing of High Performance Concrete using Super Absorbent Polymers and Light Weight Aggregare . Asian Journal of Civil Engineering (BHRC), 14(5), (2013), 773-781.

[2].Ahmaran M., Lachemi M., Hossein K.M.,\&Li,V.C., Internal Curing of Engineered Cementitious Composites for Prevent of Early Age Autogenous Shrinkage Cracking .Cement and Concrete Research, 39(10), (2009), 893901.

[3].Henkensiefken, R.,Castro,J., Kim,H., Bentz, D., \&Weiss, J., Internal Curing Improves Concrete Performance Throughout Its Life . Concrete InFocus, 8(5), (2009), 22-30. [4].Karri,K., Internal Curing of Concrete, 2015.

[5].Japan Concrete Institute., Report of JCI Committee on autogenous shrinkage of concrete. In Proceedings of international workshop on autogenous shrinkage of concrete. (1998), 5-28, Hiroshima, Japan: JCI.

[6].de Sensale,G.R., \& Goncalves,A. F., Effects of Fine LWA and SAP as Internal Water Curing Agents. International Journal of Concrete Structures and Materials,8(3), (2014), 229-238.

[7].ASTM,C. 157/C 157M-06. Standard Test Method for Length Change of Hardened Hydraulic-Cement Mortar and Concrete .Annual Book of ASTM Standards,4.

[8].Jar, P. B. \& Wu, Y. S., Effect of Counterions on Swelling and Shrinkage of Polyacrylamide-Based Ionic Gels. Polymer (Guildf). 38(10), (1997), 2557-2560.

[9].Bentz, D.P., Weiss, W.J., Internal Curing: A 2010 State-of-the-Art Review. 2011, 7.

[10].Viktor,M.,\&Hans-Wolf, R. Application of Super Absorbent Polymer (SAP) in Concrete Construction. RILEM State-of-the-Art Reports,2,(2012),13-134. 